\title{
Cuban Experiences on Computing and Education
}

\section{Tomás López Jiménez ${ }^{1}$, Melchor Félix Gil Morell ${ }^{2}$, and Adriana Estrada Negrin ${ }^{3}$}

${ }^{1}$ Universidad de las Ciencias Informáticas, Habana - Cuba, tlopezj@uci.cu

${ }^{2}$ Universidad de las Ciencias Informáticas, Habana - Cuba, rector@uci.cu

${ }^{3}$ Universidad de las Ciencias Informáticas, Habana-Cuba, adriana@uci.cu

\begin{abstract}
In 1959 in Cuba, there was little knowledge regarding modern computing; the educational offerings at the university level were not enough and the diversity was low. Currently, this environment has changed completely obtaining levels over world average standards. Apart from the collaboration from abroad that the country has received, the domestic development has played a vital role since the 1960s. The main events on industrial and scientific development on computing in Cuba and its teaching at all educational levels in this country appear in this work. We show the issues that reflect how the early and systematic guidance and attention from the country's administration, together with the active and certain academic and scientific policy of the University of Havana were highly decisive. Although the main research covers through the mid 1990s, we also demonstrate the early events that would be of interest.
\end{abstract}

Keywords: Cuba, Computing, Informatics, Education, Science, Technology, History

\section{Introduction}

The history of computing still offers a passionate, important, and greatly needed research field for society, in which many events and approaches remain almost unknown or completely non-investigated. A large number of authors have given significant and valuable results on this field, with papers scoping different approaches of the development of science, technology, economics, and society itself. Generally, their foundations rest upon well-intentioned and recognized interests; however, they do not always focused on finding answers that can be of great use and impact to improve the needed knowledge for a better human development. 
From the historiography point of a view, there are many publications, most of them of great value, which report related events from the United States, Great Britain, Germany, Spain, some information from the former Soviet Union, Japan, and some other countries. In most of them, they use history to identify and reward pioneer personalities for their scientific and technological contributions; a similar situation results when they refer to countries, historical events, universities, research institutions, enterprises, or other entities. Some accounts even focus on technological generations, platforms, crises, and the software industry. It is quite common to find the presentation and defense of preconceptions and points of views somewhat unethical or even wrong, whether unconscious or on purpose.

Yet, it is quite difficult to locate a set of approaches that provides a platform of knowledge that facilitates the needed establishment of professional culture. Similarly, it is not easy to find the horizontal and vertical integration of learning within the undergraduate, post graduate specialized studies of computing and informatics, and at the same time, support the didactics and other pedagogical needs. This situation is even more critical when it refers to establishing a general and basic culture in this history for professionals from other working fields, which is without any doubt well needed.

This void is even more important when its intention is to address the measurement and understanding of economical and social impacts of computing and informatics. The relationship between both origins, human beings and informatics, should take into account the cognitive informatics approach [1]. That is, we should consider its role through the creation of a knowledge society and the thesis that it could generate a scientific revolution that could be the basis for a new social mode of knowledge production.

Nevertheless, this paper does not give solutions to problems mentioned above. It does compile some preliminary and partial results from the research on the history of informatics in Cuba. It offers some elements that address and contribute to the veracity of the events and the motivation and importance of the investigation itself. We pay special attention to the period from 1959 until now. We also show the basic elements from previous years with an emphasis to the ending of the past millennium.

Taking into account the scope of the HCE3 as part of the IFIP WCC 2008, the second section of this paper limits its contents to the period from 1959 to 1990 . It depicts the implementation of domestic hardware and software capacities, while highlighting the main elements of computing education and training development between 1959 and today and we show its close relationship with the mentioned capacities. It is important to highlight how the Cuban government and specifically the further vision and systematic attention of its main leaders, have guided this process to foster a national development of its educational system in particular. 
On the other hand and as a necessary terminology explanation, the nouns computing, informatics, and information technology appear in this paper in an indistinctive way, as synonyms of the name of the discipline of computing, having an analysis of the backward scope and a look to the present use since its origin as automatic electronics computing back in the 1940s. We give greater preference to the term informatics as the discipline whose working field is defined by cognitive informatics [1], considering it a more comprehensive phrase and having possibilities of a longer use. In addition, it offers a more practical and widespread reference for the research of this history in order to fulfill the objectives and reach the approaches stated in this paper.

\section{Establishing Computer Capability in Cuba}

\subsection{Antecedents and Situation of Computing in Cuba during 1959}

On January $1^{\text {st }}$ of 1959 in Cuba, there were three public universities: the University of Havana (UH), the Eastern University (EU) and the Central University (CU). There were three other private universities, out of which the Catholic University of Villanueva (CUV) was the most outstanding. Before 1959 there were less than seven million inhabitants in the island; nowadays this population has stabilized having around 11.3 million inhabitants. The illiteracy rate at that time represented more than the $14 \%$ of the population. However, two years later, it reduced to a $3.9 \%$ because of a special literacy campaign carried out during 1961.

There are documental records regarding conventional data processing in Cuba from as far back as 1927; yet, in 1959, there was no established knowledge about modern computing. In 1927, IBM opened a field office in Cuba, the $27^{\text {th }}$ outside the USA. One of its main recorded external business milestones was the installment of their tabulating and accounting machines in Havana. It is recorded as the $16^{\text {th }}$ and the confiscation of their offices in Cuba in 1961 as the $52^{\text {nd }} .1$ Actually, there was no confiscation; the manager paid employees, closed all operations, and abandoned the country. Later on, the Cuban authorities reopened the place and managed to maintain its services, even though it was impossible to acquire spare parts or new equipment and systems [2].

At the end of 1958, the first electronic computer arrived in the country; it was a RAMAC 305 with $350 \mathrm{C}$ magnetic disks - at the time still considered a world

\footnotetext{
${ }^{1}$ See frequent asked question about IBM in at http://www-03.ibm.com/ibm/history/documents/pdf/faq.pdf
} 
novelty. ${ }^{2}$ This was installed in 1962 after a proposal made by the Minister of Industry, Commander Ernesto Che Guevara. Initially, the government used it for processing social security information, for the development of applications as payroll calculations, and for other enterprise interests. It was also devoted to the training and development of programmers and system designers. With the breaking-up of diplomatic relations with the USA administration along with the harsh blockade imposed by them since February, 1962, access to North American science and technology was cut off, making it also harder to establish relationship with other countries. This and other related damages have brought about accumulated losses to Cuba for over 89,000 millions dollars throughout its fifty years of existence [2].

Before 1959 there existed a baccalaureate degree in Physics and Mathematical Sciences with subjects as mathematics and statistics at the UH and the CU; electrical engineering was also taught at the University of Havana since 1900. Linear algebra and notions of operations research were part of the curriculum at the CUV while the CU started electric engineering in 1960. The EU added mathematical studies in 1968 and electrical engineering in 1969.

\subsection{Creating Basic Conditions. Period from 1959 to 1967}

In 1959, wide-ranging transformations occurred in the country. They established a National Education system with universal and free access to all citizens. At the same time, the government implemented a program on Integral Teaching Reform. The universities were the main scenarios of the process. By June of 1961, the government proclaimed a law for the General Nationalization of Education. This law established the responsibility of the state for offering free educational services. On January 15 of 1960, Commander in Chief Fidel Castro stated, "The future of our Nation has to be, necessarily, a future of men of sciences, of men of thinking..." From the very beginning the mission and commitment of science and education within the Cuban society was clearly stated.

In March of 1962, Commander Ernesto Che Guevara, with an acute vision, pointed out electronics as one of the four fundamental lines for the future industrial development of the country. They created the Department of Automation and Electronics of the Cuban Industry Ministry right away; its mission was to train leaders and professionals who would establish working and research models on the fields of electronics, cybernetics, automation, and computing [3]. In 1963, making emphasis on his idea, he stated “...in the future,

2 See IEEE Santa Clara Valley Section, Dedication: May 26, 2005 at www.ieee.org/organizations/history_center reporting that the IBM 305 RAMAC was commercially delivered from September 4, 1956. 
no country can move forward if it does not develop the Electronics and Computing fields; this is the strategy and we have to work towards it" [4].

Preceded by the use of the RAMAC 305 since 1962, in 1965 the English second-generation computer Elliott 803B was installed at the National Calculus Center (NCC) of the UH. They purchased this computer as part of the scientific equipment for the National Scientific Research Center of Cuba, also inaugurated in 1965. Working jointly with national institutions, applications were developed to enhance projects such as the transportation systems, input/output models, mix balancing and optimizing, management of bird keeping farms, numeric forecasting of time, and geological research. The NCC trained its own programmers and system analysts, and from their clients or customers. In 1967, the School of Mathematics from UH founded the Institute of Applied Mathematics and Computing to increase the academic activities and services from the out-coming scientific discipline [5].

Although before 1959 one of the Cuban universities trained electrical engineers, two of them trained Licentiates in Physics and Mathematics. Furthermore, another one taught linear algebra and notions of operation research. We can undoubtedly stated that up to that moment there were neither academic nor research activities in the country that would develop capacities for the use and development of electronics in computing.

Because of the educational reform, the scientific policy and the industrial development started in 1968 was already in existence. It had gathered the basic and indispensable knowledge necessary to undertake a more advanced development and use of computing, as well as the training of specialists and scientists in this field with higher goals set for it.

\subsection{Explicit Takeoff Strategy: Period from 1968 to 1976}

Taking as the starting point the advances reached in the knowledge of the use of computers during the eight years gone by, coupled with the objective of strengthening its development for the interest of the economy and the Cuban society, in the period between 1968 and 1976, this led to the following parallel and complementary lines.

1. In charge of the Central Planning Board became the present Ministry of Economy and Planning. Originally, its mission was to carry out the 1970 population and housing census, and also to do the centralized statistical planning and control of all the national activities. With this purpose in mind since 1968, the Board organized the National Calculus Plan (NCP) and later on the National Direction of Electronic Calculus. The country imported both the technology and the technical assistance.

2. The second line for the creation of computing capacities in Cuba stimulated and empowered domestic scientific and technological development. 
Conceived and aroused by President Fidel Castro, by the end of 1968 he entrusted the task to the University of Havana, with the immediate goal of developing a Cuban computer; this constituted a great challenge for the young scientific and technological policy of the university [6].

3. The bodies of defense and national security led the third line. Besides its own strategy and guidelines, it supported itself on the previous lines and on the collaboration of the European socialist countries, mainly that of the Soviet Union.

\subsubsection{Brief Summary of the Main Activities Developed by the NCP}

The NCP reached certain agreements in 1968 with the French government for the supply of two SEA 4000 second generation computers, followed in 1972 by two IRIS50 mainframes and little more than a dozen third generation IRIS10 minicomputers. Part of the IRIS10 were remote satellite terminals: three destined to the universities and the others to other organizations, most of which were already using the Cuban CID 201 minicomputer A and B, among which we can mention the University of Havana and the headquarters office of the sugar industry.

The two SEA 4000 were destined mainly to the processing of the 1970 population and housing census. Later on, they placed it into the service of the army with the incorporation of the IRIS computers since 1972. The introduction of French technology ended around 1975 with two additional IRIS50. The project and development of a tele-transmission system and a teleprocessing of data with these systems took place in the years between 1973 and 1976. The French alternative had begun between 1973 and 1974 to replace them gradually by a more viable and secure option with the European socialist countries. The use of mainframes continued spreading through the importation of various models of the unified series $\mathrm{ES}^{3}$ from the member countries of the Council for Mutual Economic Assistance (CMEA or COMECOM as also was known) mainly the Soviet Union, the Democratic Republic of Germany, and Bulgaria, adding up to more than a hundred systems by the end of the 1980s.

A training process of some dozens of programmers and analysts preceded the introduction of the French technology. This initiated in 1969 by recruiting first year university students who were previously studying different undergraduate

${ }^{3}$ The ES systems were developed starting in 1969 under the agreement of the European countries members of the Council for Mutual Economic Assistance (CMEA). At the beginning only to mainframe computer were orientated. The Standard for functional analogies was established for IBM 360 and 370 Systems. The main models for this serial used in Cuba were 1020, 1022, 1035, 1040 and 1055. In 1973, the agreement was expanded with the introduction of the SM system for the unification of the minicomputer development. Cuba enters to this last amendment in 1974. 
disciplines. In the beginning, they studied and were trained for programming and setting programs in machine code and assembly language for the Elliott 803B and the SEA 4000, respectively, for the AutoCode Elliott 803 Mark 3, and ALGOL 60 for the Elliott 803B. This personnel training was kept according to the needs to assimilate the IRIS computers, firstly for a pioneer small group in France and then in Cuba. Some specialized schools from the University of Havana and the Central University, trained their students and teachers for a while in the use of the IRIS 10 , though the training was limited due to the fact of having only a few of those minicomputers.

Aiming to increase the range of organization in the country and its economic and social development, they proclaimed a new law for the organization of the central administration of the Cuban state in November of 1976. Because of it, the government created new ministries and organizations; priority for the development of computing increased significantly by creating the National Institute of Automated Systems and Computing Techniques (INSAC) that represented a special body of the Council of Ministries. Its main objective consisted of paying special attention to the development and generalization of computing in Cuba in all their lines - hardware and software industries, applications, technical services, imports, exports, and others. From that moment on, the NCP and the rest of the specialized computer institutions became part of INSAC, thus integrating themselves into new conceptions and programs. Education was empowered with the creation of the Ministry of Higher Education, expanded from the Ministry of Education from that moment onward in charge of the other subsystems of education.

\subsubsection{National Trend of Scientific and Industrial Development of Computing}

In April of 1969, the UH created the Digital Research Center (CID - acronyms in Spanish), having as an immediate assigned mission for the development of a Cuban computer. Led by the magnificence of Ph.D. Eng. Orlando Ramos Fernández (1938-1990), on April 18, 1978, the CID 201 was running, the first third generation Cuban minicomputer, with integrated DTL circuits and $4 \mathrm{~K}$ words of a 12-bit ferrite core memory unit. For its architecture, it used the PDP-8 as a reference. In October 1970, five years before they reported the $\mathrm{KCS}^{4}$, a compact audiocassette recorder was coupled to it as a more powerful I/O device, at a transfer ratio of 300 bauds; it was ten times faster than the original paper tape and had an auxiliary $64 \mathrm{~K}$ words memory -equivalent to $96 \mathrm{~K}$ bytes [7].

${ }^{4}$ See the KCS (Kansas City Standard), reported in BYTE February 1976. Afterwards the Processor Technology Corporation published the popular CUTS- Computer Users' Tape Standard, with option of 300 or 1200 bauds. 
The production of the CID 201 started by the end of that year under the name of CID 201A. What made it different was the technological solution offered to its cabinet and wiring for a more efficient reproduction, enhancing its coordination and facilitating a man-machine communication as shown in Figure 1. We can see how it integrated the operator control console to the main body. Replicated through small neon lamps, in the console there are the binary contents of the arithmetic unit accumulator and its a bit link, the memory/address contents and the program counter registers, as well as six keys to interact with them in the setting up, debugging and running of the programs and the technical service. On the right frontal block, they installed an original $\mathrm{I} / \mathrm{O}$ system as an alternative solution to the difficulties faced to obtain peripheral equipment due to the North American blockade against the country. The I/O system also maintained the monetary waste within the limited disposition of the project and of the country. Its output unit consisted of a decimal numerical display initially with tubes of seven segments. A luminous $4 \times 4$ dot matrix made it possible to correlate the numerical result of 16 tags or names of different variables - alphabetical or personalized - according to the case. The input unit was an integrated device with a conventional decimal numerical keyboard and three hot keys for the automatic launching of three different programs. This device, together with the corresponding programs, favored an economical and flexible I/O interactive system in octal, decimal, and symbolic characters for multiple purposes, including the setting up and debugging of programs.

The right side of Figure 1 shows the compact cassette audio recorder /reproducer for which the necessary communication protocol was developed in a binary format. In its configuration, there was also included a tele-printer with a five-channel paper tape reader and punch in the Murray code, produced by the RFT Complex of the former Democratic Republic of Germany.

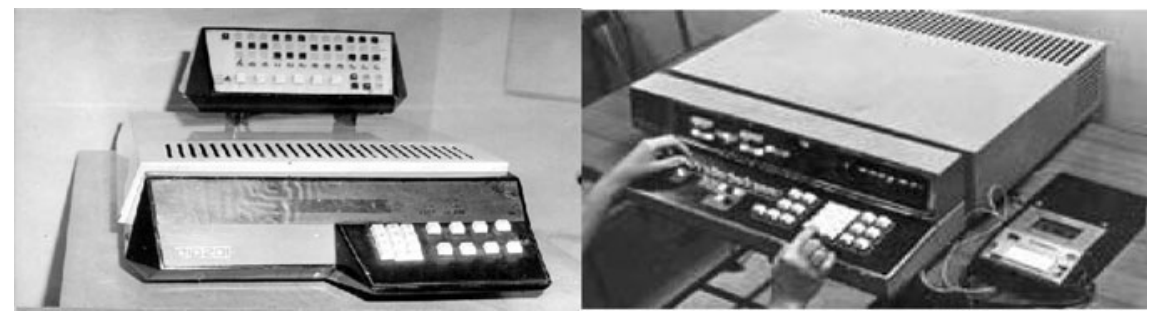

Figure 1 First Cuban minicomputer. Left hand: Prototype CID 201. Right hand: Serial model CID 201A.

Having no access to US systems and facing program incompatibilities became a challenge for the fathers of the CID. Late in 1970, it released the domestic software for bootstrapping, input/output, and integer and floating-point arithmetic 
package. Early in 1971, it received the LEAL 201 (which in Spanish stands for algorithmic language, an auto-code language of high level, domestically designed; for whose development it was followed some concepts from Auto-Code Elliott 803- Mark III). In 1972, it had incorporated a compiler and an interpreter from a simplified FORTRAN and other library programs.

The next code is a sample of a LEAL 201A program implementing Euclid's algorithm to obtain the GCD of two integer variables. Note the use of Polish notation. The comment facility was not implemented; here it is used for clarity purposes and appears at right side of the code, beginning with the slash character.

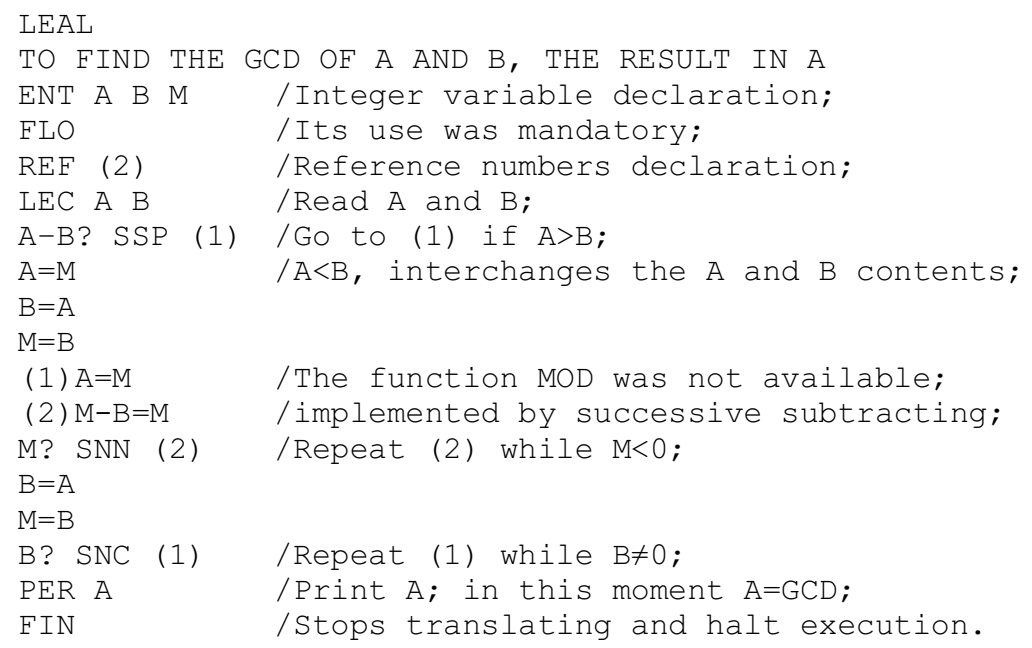

Following research goals, in 1972 the experimental minicomputer CID 202 was finished. Its novel architecture allowed running two programs in parallel, using a common $16 \mathrm{~K}$ central ferrite core memory unit with 16 bits words, having the possibility of giving control and resources to one of them. Its operator control console allowed two programmers or operators working simultaneously, interacting each with their respective programs.

By the end of 1972, CID 201B was completed; it had twice the speed of the $201 \mathrm{~A}$, with up to $32 \mathrm{~K}$ by $4 \mathrm{~K}$ modules, eight auto-indexing registers per module, having an interruption system and a direct access bus. Its development extended until 1976 under a particular concept of family of systems, reaching configurations of even four units of minidisks and magnetic tape mini-units, operating systems with a DOS version included, and a system of files management on magnetic tape with an original algorithm of direct access from the FORTRAN IV. In Figure 2 the central processing unit of the CID 201B is shown with possibilities of maximum configuration. In the left cabinet we see the central processor and the central memory, allocated up to $32 \mathrm{~K}$ words of 12 bits. They placed the 
multiplexed channel bus and the disk unit controllers, magnetic tape units and other optional expansions in the right cabinet.

Its software included a powerful FORTRAN IV compiler. They also developed ALGOL 60, FOCAL, BASIC, SNOBOL compilers, and a COBOL compiler that was more powerful than the DIBOL of DEC.

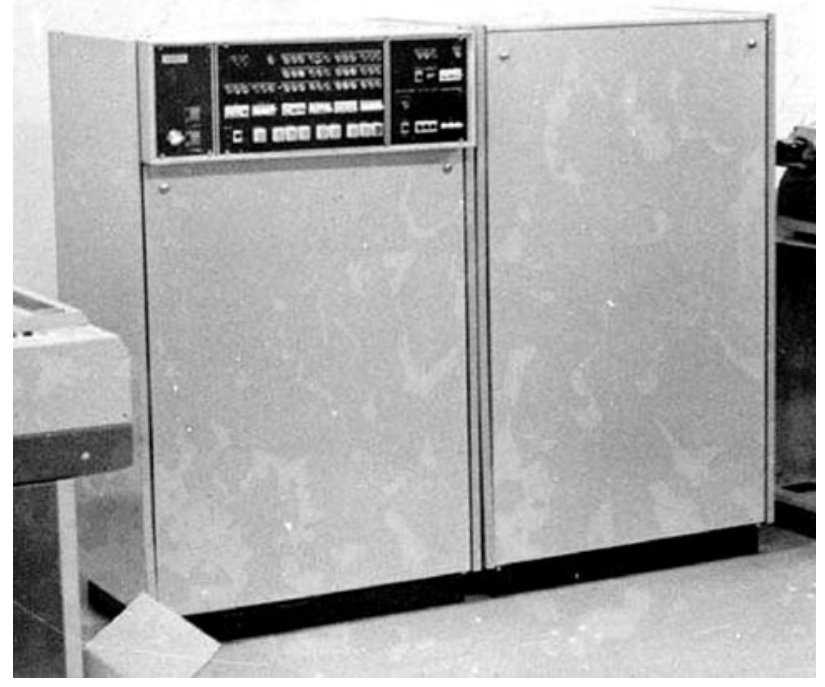

Figure 2 Cuban minicomputer system CID 201B.

They used a self-developed LALR1 analyzer. Specialized languages included LEE for the electrical industry and LINCO for the teaching of computing at the intermediate level, with a multi-terminal configuration in shared time.

The FORTRAN IV compiler was entirely compatible with the ISO standard for FORTRAN IV full version. It generated an object program for an original virtual machine designed with the purpose of raising efficiency in the use of the hardware system resources. In a benchmark test to measure and compare the speed in the execution of programs, those written in this FORTRAN IV surpassed by more than 2.5 times the equivalent solution in the other languages and compilers implemented. A fast algorithm for binary-decimal conversion of variable speed for all the representation formats was also developed, reaching a minimum of 220 characters per second and a maximum higher than 1800 . The virtual machine also made it possible to implement recursive subroutines and other novel characteristics for the time.

Following the most innovating trends, in 1973 they defined the CID 300 family of minicomputers under the basis of reaching total compatibility of programs with the PDP-11 family. Production started in 1976, gradually substituting the 
production of the 201B. This system fulfilled the SM standards of the CMEA (COMECON). As part of the system, they developed a wide range of video terminals. These emulated efficiently several of the VT DEC models, including the VT-220. The line of video terminals and keyboards became a Cuban specialization within CMEA, exporting thousands of units to the European socialist countries, mainly to the Soviet Union.

The system software CID 300/10 fulfilled the SM standards, equipped with operating systems of real and timesharing. Among the languages, $\mathrm{C}$ and Pascal were included besides those traditional ones. The Cubans were in charge of the development of an original COBOL, complying satisfactorily with the international tests of the CIC's CCP/SM. From that moment on, it was included in the software distributions carried out by the European countries of SM.

Among other developments more oriented towards applications the GES 300 system; the multi-terminal SMT 300 and the system of data base management dBASE 300 were included.

Figure 3 shows a calculus center with a CID 300/10 system in a basic configuration with a unit of minidisks with a fixed disk and an interchangeable cartridge. We can appreciate some other equipment such as a video terminal as an interactive console, 180 characters per second mosaic printer, and others. The tallest cabinet in the middle lodges the central processor, the memory unit, the main minidisk units, and other interfaces. The configuration of the system augments adding similar cabinets for lodging up to four units of minidisk, four units of magnetic bands, and other optional equipments.

The hardware development and production was not limited to the system of minicomputers. From 1974, work started on microprocessors for multiple purposes, including diverse microcomputers. Among them was the CID-1417, compatible with the IBM PC/XT. They also developed different systems for the industrial automation and other processes such as for medical computerized equipment in conjunction with other research centers and medical assistance institutions. Research on advanced medical equipment and applications began since the early 1970s. An important stage was marked when they delivered in 1982 the MEDICID 03. It was a computerized system for advanced brain research. The development of complex medical equipment and automated systems turned into the current specialization of the ICID (originally CID). With its serial productions, it supplies the national health system and increasingly exports to various countries. This alternative became a specialization reached within the CMEA and maintained until 1991, the year in which Cuba supplied some medical computerized equipment to the former Soviet Union.

Since 1970, CID produced its own minicomputer systems in laboratories and workshops of its principal site. Until 1973, through the development of their own technology, they built a first factory and started producing in the industrial area of 
the vocational school "V.I. Lenin" High school. Students participated in the production lines as part of their education. This experience provided them with excellent results in their future studies as professionals with a deep and advanced theoretical and practical knowledge early in their lives.

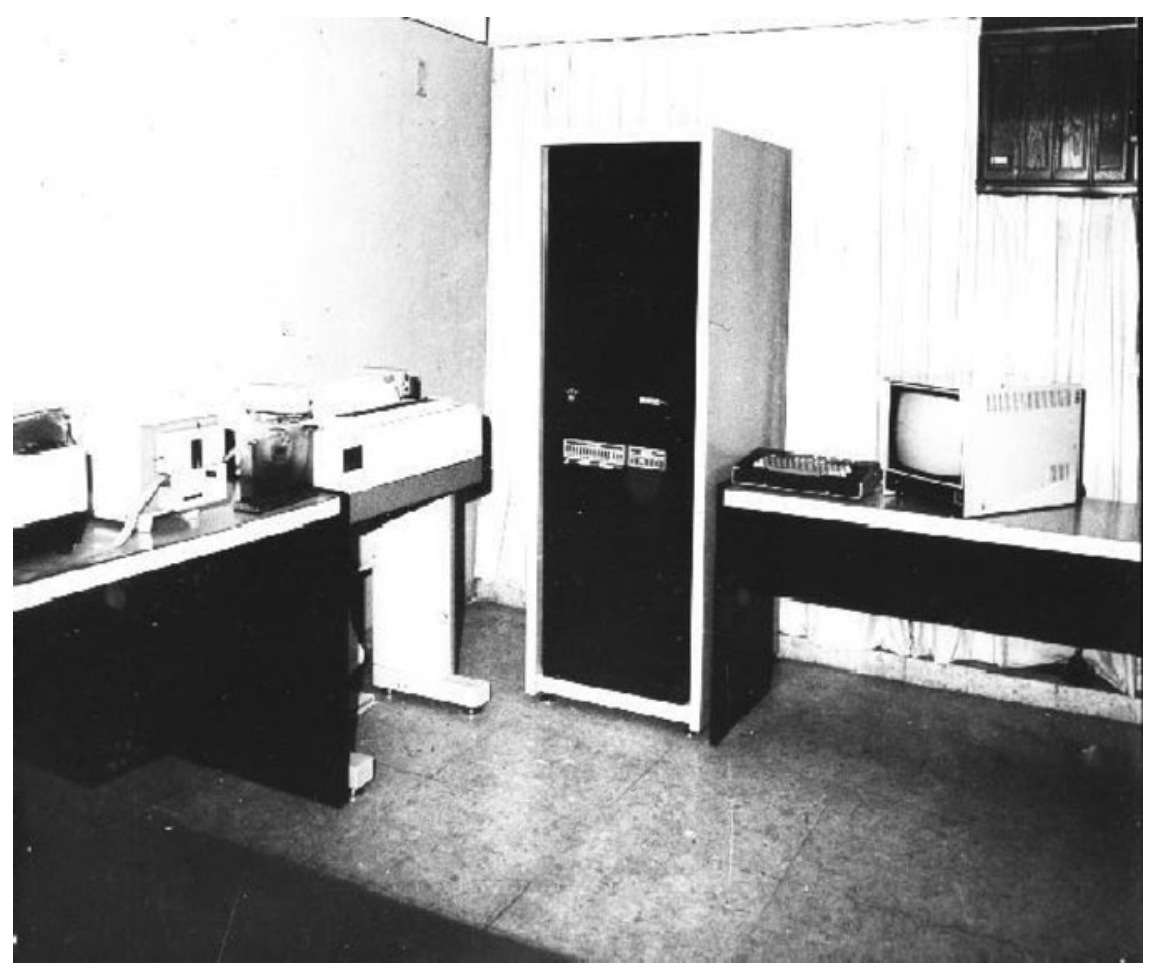

Figure 3 Cuban minicomputer system CID 300/10.

\subsubsection{Development of Computing by the Defense and National Security Bodies}

The Cuban defense and security bodies had developed their own computing strategy since 1959. Though facing hazardous situations and many disadvantages, they have been able to keep themselves updated in the computing science and technology fields as an important part for ensuring the freedom and sovereignty of the Cuban nation. Their conceptions, plans, and performance had equaled to what more developed countries have done. They encouraged, supported, and 
cooperated with the civilian institutions in charge of science, technology, and industry by responding with necessary and convenient services.

They created and developed their own systems and schools for teaching and training their human resources. They were the pioneers in the country creating the undergraduate studies on computing, founding in 1969 computing engineering at the higher Technical Military Institute - the first Cuban military university. Some years later, this discipline converted to one called Automated System Engineering. In addition, they were the pioneers in cooperating and introducing in Cuba the Soviet computing science and technology, effectively contributing to ensure their strategic activities.

\subsection{Collaboration on Computing with the CMEA countries}

In the early 1960s, the collaboration with the former Soviet Union was established. It became a very important and vital alliance for the development of the country during a long period. Nevertheless, CMEA did not accept Cuba as a full member until 1972, the moment in which they classified it as one of the three countries less developed of the agreement, jointly with Viet Nam and Mongolia. Opposite to what happened with the collaboration with many other economic and social sectors, it was not until this moment that gradually opened doors to the computing one.

In those times, a parallel committee to CMEA, the Intergovernmental Computing Committee (ICC), established in 1969, carried out the international socialistic collaboration for the computing development. Cuba was included in the ICC after the CMEA admission as full member, first as a future client of EC (US Unified Systems), whose first deliveries started at slow rates since 1974. In 1973 the ICC extended the scope of its program, organizing the Main Constructors Council (CCP-SM as in Russian language), for joint development of the unified minicomputer systems, with the SM as general mark; the strategy of this Council was to achieve the full functional analogies with the Digital Equipment Corporation's PDP 11 minicomputers family. Once Cuba became part of this Council in 1974, it already had its own development in this field, as discussed in subsection 2.3.2 above.

In general, the autochthonous Cuban minicomputer software development and knowledge, in conjunction with their application in several social and economic sectors including education, were relatively more advanced than in the rest of the socialist countries of the Eastern Europe. They found a very similar behavior with hardware lines starting in 1969 in Cuba, especially in comparison with the knowledge about some of the leading DEC standards. This position happened in a very poor and more difficult condition that was different from that of those 
countries. The same occurred regarding the relative incipient microprocessors knowledge.

We now summarize briefly some examples to support the above affirmations.

- In March of 1973, when in Bulgaria they were starting up its IZOT 310 minicomputer - similar to the PDP 8 - the Cuban CID 201B was already running with the full memory unit working and the original basic software delivered.

- The same situation occurred in the Soviet Institute INEUM in Moscow, headquarters of the CCP-SM, when they were starting up the initial series of the SM-3 central processor - similar to the PDP 11/05 central processor. The Cuban engineers demonstrated that they were much more skilled than their Soviet partner was in solving complex problems, based on the knowledge of architecture they had from their studies that started since 1972.

- The software platforms for the European SM systems were mainly directly assimilated from the DEC development. However, Cuba developed the COBOL compiler and other original software products and, consequently, Cuba supplied them to the member countries of the SM agreement.

Nevertheless, some authors claim that Cuba developed its computing industry thanks to the European socialist help with the projects and the technological supplies. They also strongly state that the Cuban computing professionals were, in a massive way, educated and trained in the former Soviet Union and some other European socialist countries [15]. In this paper, we offer some details on how the history occurred. Apart from the negative factors that could have been present, the cooperation Cuba received from those countries represented a big importance and good contribution to the Cuban science, technology, and economics. Concerning the human resources education and training of the computing professionals and technicians in Europe, it was in a low percentage with respect to rate of people educated and trained in the country, even when its quantity in total terms was something greater since the second half of the 1970s.

\section{Spreading Computing Teaching in Cuba since 1970}

In 1970, the UH created the Computing Committee (CCUH) to widen research activities on this field, such as industrial development, applications and their teaching all over the country. During the academic period from 1970 to 1971, the UH set up programs for computing science (CS) and computing engineering (CE) undergraduate studies; this occurred only five years after the funding of first computing science department of the world at Stanford University. Students, who had an engineering specialty and who had finished their $4^{\text {th }}$ grade in 
telecommunications or automatic control studies, had credentials for the CE; this last program became a full-time study by 1972. In 1970, the UH included the CS in mathematics bachelor degree studies. That same year, it introduced Analysis and Programming in FORTRAN IV as a subject taught at several universities and the CID opened a master degree program in digital systems in joint collaboration with Canadian universities.

The Professor PhD. José Antonio Presno Albarrán represented the School of Medical Sciences in the CCUH from its very beginning. Immediately, he organized the Computing Department at his school and increasingly added this subject into the curriculum. In 1974, he published "Cybernetics: Computers at Health Systems". In the 1970s, the Cuban Association of Medical Informatics was founded [10].

Since 1970, the CID started to deliver courses on operating systems, programming, applications, and technical services to their clients' staff. Since February of 1971, the first CID 201A was used on sugar cane train timetable planning and control systems and on the balancing and accounting of row material in process at "Camilo Cienfuegos" Sugar Cane Factory.

Since its very beginning, computing teaching on high education in Cuba followed approaches corresponding to those from international practices. The $\mathrm{UH}$ played a transcendent role since the 1960s. Nowadays, the universities have multiplied themselves by more than 20. Creating municipal universities to generalize high education system meant a growth in the enrollment to 700,000 during 2007 to 2008 in a country having only 11.3 millions inhabitants.

Informatics teaching in the other educational subsystems was also a national strategy since the first half of the 1970s. In 1972, in a visit to CID, Castro expressed, “... Comrades, I have come after seeing that computer (he meant the French IRIS 50) where you could hardly have access, where the people have no access, to ask you to make many computers for the people, so that the students have access to them, study them, learn computing. We are a country without natural resources, but we have a very important resource, the intelligence of the Cuban people, which we have to develop and computing accomplishes that, and I'm convinced that Cubans have a special intelligence to master Computing" [6].

From then on, attention focused on the evolution of this teaching in Cuba through the mid-1990s, and some transcendental events from the current century are also shown. We make the analysis based on the development and improvement of:

- Higher education in Informatics since 1970

- High school teaching since the first half of the 1970s

- General education since kindergarten

- Education and continuous training for all 


\subsection{High Education in Informatics since 1970}

The first stage occurred through the consolidation of the computing bachelor degree studies and engineering took place between 1970 and 1976. Topics concerning solid state and microelectronics were included in the specialties of electrical engineering and physics, supported by researches and postgraduate studies from CID, the Solid State Research Laboratory (SSRL), and the Microelectronics Research Centre (MRC), together with all laboratories from the $\mathrm{UH}$.

In April of 1970, the School of Technology of the UH created the Engineering Systems Study Centre (ESSC) to guarantee the inclusion and development of computing teaching to the different undergraduate disciplines, postgraduate courses, and to the professional practice as well [8].

In order to face the increasing number of $12^{\text {th }}$ grade graduates, the government created new universities with more capacities within them. In June of 1976, the School of Technology of the UH became the Higher Polytechnic Institute "José Antonio Echeverría", (ISPJAE in Spanish); in 1977 studies of Automatic Systems Management Engineering began (SAD as in Spanish) with freshman and sophomore students reaching its first graduation in 1981. Their final profile turned out to be very similar to the American recommendations for information systems engineering. ${ }^{5}$ Since 1990, such studies were renamed informatics engineering [9].

In 1982, higher pedagogical institutes included the bachelor in mathematics and computing as undergraduate studies for high school teachers. In 2000, a bachelor on informatics became an option to more than 10,000 computing teachers of that level. We must also mention the special program carried out to train the emerging informatics teachers at the beginning of the present century to guarantee the opening of municipal schools or the Cuban universities and for the spreading and introduction of the computing teaching in the national K-12 system.

The Informatics contents within the curricula of the medical sciences studies evolved systematically, incorporating subjects such as biostatistics and computing, network use, and other related topics. That situation remained the same until the discipline of medical informatics was created and consolidated in 1998; this discipline was later included within the nursery bachelor degree studies and its director plan was established for all medical sciences [10].

The outstanding development of the Cuban national health care system implemented the use of a growing and extended assortment of medical devices, imported or developed and manufactured by the country's institutions; by this means, it generated an important demand of a specialized professional. In 1989, the High Institute of Medical Sciences of Havana, experimentally started the

\footnotetext{
${ }^{5}$ See "Computing Curricula 2005. The Overview Report covering under graduate programs. The Joint
} Task Force for Computing Curricula 2005. A cooperative project of ACM, AIS, and IEEE-CS. 
health technological bachelor course; since 2002, this successful program had spread to various similar institutes, expanding to twenty-one different profiles from its initial six. In most of them, computing and informatics contents played an important role, some of them are fully specialized in these disciplines [16]. Similar motivation led ISPJAE to establish the biomedical engineering studies in the School of Electrical Engineering in 2005 [17]; simultaneously, they implemented it also at the CU and at the EU [19].

The curricular programs for the Cuban higher education had the names A, B, C... according to their generation. In 1985, the enhancement of A and B plans began, in order to achieve higher integration and a better relationship to practice, pursuing, among other objectives, to produce graduates that are more suitable. From 1990, they introduced C programs, cutting the unnecessary disciplines, achieving a greater coherence and systemic scope [9].

Thus with the economic changes, with the new informatics Cuban software industry strategy, the computer machines and equipment and the electronic components engineering studies disappeared; the necessary contents were included into the studies of automatic engineering and electronics and of the telecommunications engineering studies as well. The computing bachelor studies began in 1970, which they later named cybernetics, finally changed its name to the computer sciences bachelor from C plans since 1990. Indeed, they also intended such changes for curricular updating and adjustment. Following similar criteria, the informatics engineering model and curricula were updated to a $\mathrm{C}$ program in 1990. These studies started at 1977; they gradually spread to the Cuban provincial universities, reaching the whole country by 2005 . Since 2003, the ISPJAE opened these studies at all municipalities in the capital under a blended learning system. Today, there are numerous master and doctorate degree courses in many Cuban universities, some of them in jointly modules with other countries' academic institutions.

The University of Informatics Sciences (UCI in Spanish) was founded in September of 2002, starting its first year with 2000 students. On July 19 of 2007, 1334 students graduated as informatics sciences engineers. Its present recruitment consists of eleven thousand students spread within thirteen schools, ten of them on its main campus and three in different territorial allocation all along the country. The schools' main differences occur by their second profile of specialization. Other distinctive elements are for example: the discipline of professional practice with subjects all along the five years syllabus; the learning model comes from production and research activities and organizing students' work in teams playing different roles. An optional subjects program exists including level assessment, a kind of certification exams. Continuous curricular improvement has become important. Its own name encourages people to think differently. 
The main speech delivered during the first graduation ceremony of this young university literally stated, "The UCI has been born for socializing and multiplying as never before the higher informatics studies in Cuba. In five years, the country grew from 2483 to 16395 undergraduate students in computing, multiplying the recruitment in these disciplines almost seven times. Together with the young students from junior high studies on informatics, it represents a force of more than 50000 young people committed to the main idea of transforming the informatics field in the most productive and resource supplier sector for the nation, using the intelligence deeply" [18].

\subsection{Junior High Education from the First Half of 1970s}

In 1970, the Ministry of Education organized a group for the development of computing in interaction with the $\mathrm{CCUH}$; its mission was to prepare and develop the initial strategy for the use of computers in education and their introduction into experimental teaching in three of the six sub-systems that integrated general education $\mathrm{K}-12$ system.

In 1971, the CID concluded the FOCAL CID 201A compiler oriented to education, performing experimental experiences in selected schools. In 1973, it developed the Language Introduction to Computing - LINCO CID 201B, in a multi-terminal environment with time-sharing; implementation started in the vocational senior high school "Vladimir I. Lenin". There, on January 1974, during its official inauguration, in the presence of L. I. Brezhnev - First Secretary of the CPSU, Fidel Castro explained some of its achievements. He noted that the school had a calculus centre for the teaching of computing, an industrial area for electronics, with a line for assembling Cuban minicomputers and other perspectives, stressing that no country of Latin America, including the United States, had a similar school. That experience gradually extended to schools of its kind in other provinces [11].

The introduction of personal computers in this educational level began in 1983, two years after launching the PC platform by IBM. It started at the vocational senior high school "Humboldt 7", which used a CID 201B since 1979. It became the first pre-university Professional Institute of Exact Sciences (IPVCE in Spanish) in the year 1983. In a visit to its laboratories, accompanied by the President of Angola, Fidel Castro said, "Not far is the day when all our schools have the latest machines and that our compatriots use properly computers". In 1989, the conversion of all vocational schools into IPVCEs was finished and by then they obtained enough PCs.

The U.S. blockade of Cuba hampered the early spreading of these experiences due also to the lack of financial resources for the broad socio-economic Cuban 
programs. The arrival of home computers offered a better alternative for their introduction into schools. Domestic industry developed models themselves, starting a serial production by the end of the 1980 s, a process interrupted by the collapse of socialism in Europe and the deep crisis the Cuban economy had to face.

The development of specialized technological institutes continue today under the name of Polytechnic Institute on Informatics (IPI in Spanish); it constitutes a special program consisting of twenty-seven institutes, with a staffing of 27,000 students, graduated as high school technical sciences students specialized in computing.

\subsection{General Education from Kindergarten}

The Cuban children from kindergarten to the ninth grade are members of the José Marti Students' Movement and they participate in extracurricular activities as additional technical training, cultural, patriotic and sports actions. They freely offered this complement in the House of Students, those with classrooms, laboratories, or knowledge clubs (KC) for career guidance. In December 1984, they founded the $\mathrm{KC}$ of computing and electronics from the Central House of Students "Ernesto Che Guevara". This place was equipped with a minicomputer CID 300/10, home computers with BASIC, IBM compatible PC, calculators, and other electronic devices needed for children practice.

The deep economic depression in the early nineties affected the progress of this and other programs of these teachings. However, on March 29, 2002 the President of Cuba opened the "Educational Informatics Program". One of the fundamental objectives of this strategy was the computerization of the Cuban society. Currently it includes more than 774,000 children and youth of the Cuban system K-12, with an infrastructure equipped with modern computers, a student/PC twelve to twenty, depending on the education subsystem and the territory. Its general objectives are [12]:

- To support informatics training for students, starting in stages from adaptation level until mastering and application of these technologies to solve problems and to promote interest in their study.

- To develop practice and skills to work with computers and assimilate a set of basic computer concepts and procedures that will enable them to solve problems.

To guarantee the success of this educational informatics strategy, they developed several ongoing specialized programs that included educational software development and production organized as projects and collections such as the interesting "Multi-Know How" project. In those projects, coordinated by 
the education ministry, the UCI plays a protagonist role, in cooperation with prestigious Cuban pedagogical and software industrial institutions.

\subsection{Continuous Education and Training for All}

After studying linear algebra and operations research on his own in late 1964, the minister of industry Ernesto Che Guevara explained to the ministry council board the importance and need of such studies for the implementation of the computer application. He taught them an expeditious course himself, thereby heavily influencing them early in sectors such as the sugar industry, mining and geology, construction, poultry, and other areas [4].

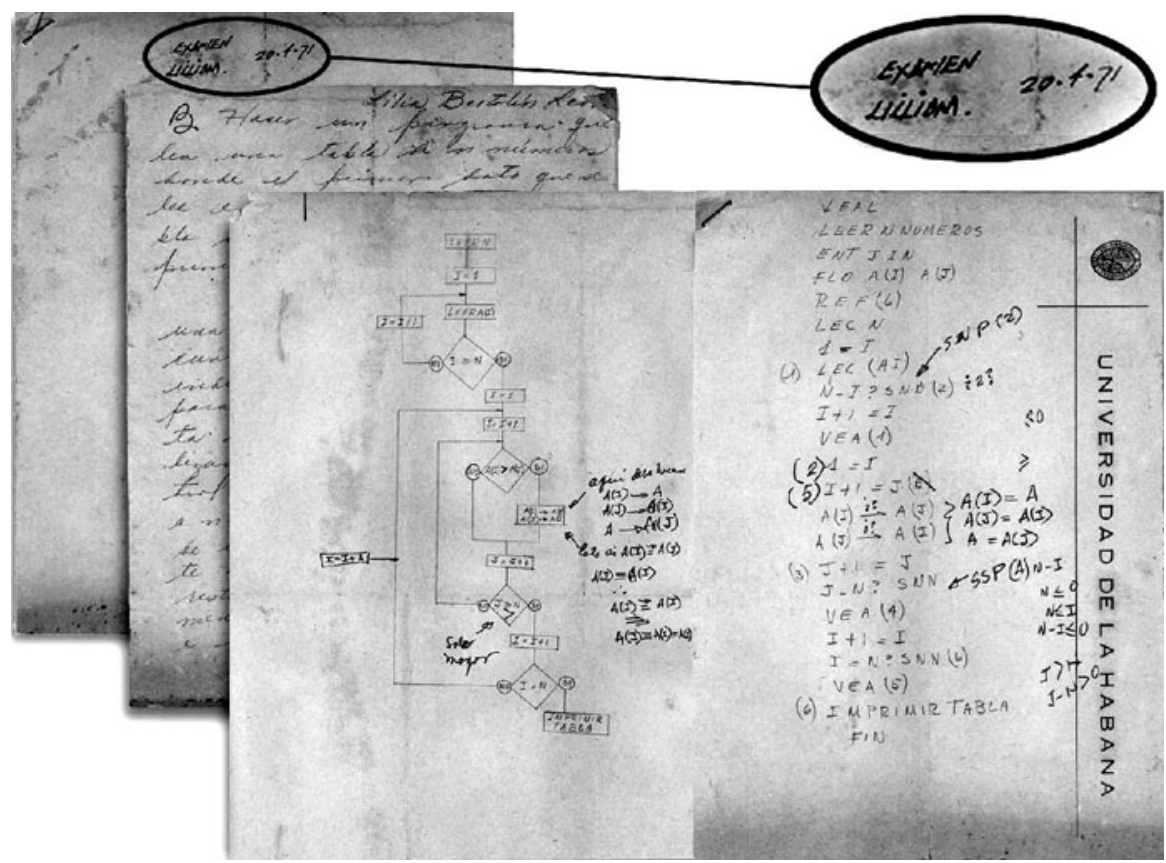

Figure 4 Copy of a LEAL 201A programming exam, made by a worker at Camilo Cienfuegos sugar factory, on April $20^{\text {th }}, 1971$.

The training department from CID was one of the pioneers in this education, starting in 1970 to offer courses to workers and specialists from the organizations that will operate Cuban computers, training operators, programmers, and analysts. They offered these courses on an optional basis in its central headquarters or in the client's sites. Figure 4 shows a copy of a LEAL 201A exam, made by a worker at Camilo Cienfuegos sugar factory headquarters, on April 20, 1971, who was being 
trained for developing future applications with the first Cuban minicomputer installed in that sugar enterprise on February 2, 1971.

Continuous education in Cuba includes a system of specialized schools by economy and society sectors for the instruction and training of workers and specialists; some of them are true high-level business schools. This system gradually incorporated computing and informatics teaching by the late 1970s.

The Computing Youth Club created in 1986, a result of the Fourth National Exhibition of the Builders of the Future, became the first Computing and Electronics Youth Club in July 1987 (CEYC, JCCE as in Spanish) [13]. On September 8, 1987, President Castro announced that the JCCE had become a national program; institutions were free and offer open access to the study of computing and its basic electronics. Since its beginnings, there were three areas: one for the introduction to computing, another for software and applications development, and the third for electronics and hardware in general. They promoted scientific and technical exchange activities, with increasing presence in national development, reaching also the most remote rural areas. In 1991, they launched the national network "Tinored" with international access, one of the first Cuban networks. There were 600 JCCE currently operating throughout the country, having an average of 3.5 clubs in each Cuban municipality; in June of 2006, they reached their first million graduates. The JCCE program continues to be a paradigm for the global population free access to computing and information on the conditions of a developing country, with a project of social justice and equality for all [14].

\section{Conclusions}

By this paper, we can see that in Cuba, in spite of being a small developing country having almost no natural resources in addition to the well-known adverse conditions, has reached an informatics development that surpasses the world average. Since 1959, the introduction and implementation of computing or informatics in the country had never been delayed for more than three or four years in comparison with the world advance level of basic platforms of software and hardware. To say it in another way, after 1970, this gap systematically decreased to not more than two years. In some instances, they developed original novelties many years before they appeared in publications abroad. Examples include the use of audio compact cassettes, the creation and implementation of a virtual machine, fast algorithms for binary to decimal conversion in different numerical formats, and other examples.

The local development has played an important role in the teaching and implementation of this discipline. It is quite possible that there is no other country 
in the world that had an education system similar to the K-12 system where all the students had plenty and free access to study and use modern informatics, supported by an official and advanced educational program. We can say the same for the rest of the educational levels and modalities on education and training of informatics as a science and technology by and for itself. The visionary and enduring priority and attention given to these matters have been essential to accomplish these goals.

Yet, we were compelled to illustrate that the fundamental strategy followed while setting the use and implementation of computing has been "social inclusion", which we can easily see when reading the given information about specialized and general education. We address these statements in a positive manner to demonstrate the existence and necessity of some of the scientific problems mentioned in the introduction.

\section{References}

1. Wang, Y.: The Theoretical Framework of Cognitive Informatics. Int'1 J. of Cognitive Informatics and Natural Intelligence - 1(1), 1-27, University of Calgary - Canada. JanuaryMarch (2007)

2. López J., T., Gil M., M. F.: Accomplishments of a Joint Cooperation Work between the Institutions of the Soviet Union and Cuba 1972-1990, Karelia - FR, Proc. SoRuCom'2006 (2006).

3. Sáenz, T. y Capote, E.: Ciencia y tecnología en Cuba, La Habana Editorial de Ciencias Sociales, La Habana (1989).

4. Figueras, M. A.: Oral Interview by a CHC61 contest team, UCI Collections Archive, La Habana - Cuba, (2007).

5. Lodos, O.: Oral Interview by a CHC61 contest team, UCI Collections Archive, La Habana Cuba, (2007).

6. López J., T.: Los cubanos tenemos una inteligencia especial para dominar la Computación Periódico Juventud Rebelde - La Habana, March 23, (2006).

7. Ball-llovera D., A.: - Reporte interno del CID y comunicaciones posteriores, La Habana, (1970).

8. CEIS: http://www.cujae.edu.cu/centros/ceis/index.htm CEIS. Accessed April 18, 2006.

9. ISPJAE: Historia. Quienes Somos, La Habana, http://www.cujae.edu.cu/wwwcujae/quienes_somos/historia.html Quienes Somos. Acceded April 18, 2006.

10. O’Farril, E., Colunga, C.: La enseñanza de la informática médica en Cuba 1993 vol. 7(2):129-35 -La Habana - Cuba.

11. Castro R., F.: Discurso la inauguración de la EV "Vladimir I. Lenín”, La Habana, Periódico Granma, January 31 (1974).

12. MINED: Informática Educativa, www.rimed.cu/computacion/web/computacioneducacionalbien.html Programa de Informática Educativa, Accessed January 9, 2006.

13. Labrada, M.: Oral Interview by a CHC61 contest team, Havana - Cuba, UCI Collections Archive (2007).

14. JCCE: La Computadora de la Familia Cubana, http://www.tribunaantimperialista.cu/Index.php?act=sn\&id=607 La Habana - Cuba (2007). 
15. Nitusov, A.: Computing Technique of the COMECON countries. www.computermuseum.ru/histussr/sev_it.htm Computing Technique of the COMECON countries. Accessed Nov 11, (2005).

16. Guerrero P., J.C. et al: Tecnología, tecnología médica y tecnología de la salud: algunas consideraciones básicas. La Habana - Cuba.

http://bus.sld..cu/revistas/aci/vol12_4_04/aci07404.htm Tecnología, tecnología médica y tecnología de la salud. Accessed January 15, 2008.

17. ISPJAE: Ver en www.cujae.edu.cu/esp/paginas/facultades/electrica.html (Consultado en enero del 2008).

18. National Statistic Office: Panorama Económico y Social. Cuba 2007 La Habana - Cuba (2008).

19. Calzadilla R., I.: Ofrecerán 52000 plazas para el ingreso a la educación superior. La Habana - Cuba, Periódico Granma, marzo 18, (2005). 